\title{
Concepts of linguistic expertise in the ordinary language consciousness
}

\author{
A. A. Talitskaya ${ }^{1}$, I. I. Ananeva ${ }^{1}$
}

1P. G. Demidov Yaroslavl State University, 14 Sovetskaya str., Yaroslavl 150003, Russian Federation

DOI: $10.18255 / 2412-6519-2020-4-396-406$

Research Article

Full text in Russian

The article points out the need to study the vocabulary that is actively used in controversial texts submitted for research by linguistic experts. The objects of consideration are concepts of linguistic expertise (swearing, invective, slander) that have a verbal expression. The features of perception of these lexemes by ordinary language consciousness are revealed. The psycholinguistic description of the studied concepts is based on the results of a psycholinguistic experiment conducted using the method of free associative experiment. The authors have compiled associative fields of lexemes, identified semantic groups and formulated psycholinguistic meanings. A comparison of lexicographic descriptions of lexemes and the experimental information. Lexicographic description of lexemes is based on both the explanatory dictionary of the Russian language and legal dictionaries, dictionaries of literary concepts, the dictionary of argo, etc. The problems of distinguishing the meanings of legal concepts and improving the legal literacy of native speakers are raised. It is shown that the studied lexemes are generally well assimilated by the language consciousness of native speakers (except for invective) and their legal aspect is partially realized by respondents. Some conclusions about the importance of conducting psycholinguistic research in the practice of linguistic expertise are made, because they allow us to clarify the meaning of legal concepts and show the features of perception of such concepts by ordinary language consciousness.

Keywords: language consciousness; psycholinguistic experiment; associative field; semantic group; expletive; invective; slander; insult

INFORMATION ABOUT THE AUTHORS

$$
\begin{aligned}
\text { Talitskaya, Anna A. } & \begin{array}{l}
\text { E-mail: cliver_08@bk.ru } \\
\text { Cand. Sc. (Philology), Associate Professor }
\end{array} \\
\text { Ananeva, Irina I. } & \begin{array}{l}
\text { E-mail: yairina.ananeva@yandex.ru } \\
\text { Student }
\end{array}
\end{aligned}
$$

For citation: Talitskaya A. A., Ananeva I. I. Concepts of linguistic expertise in the ordinary language consciousness // Social'nye i gumanitarnye znanija. 2020. Vol. 6, No 4. P. 396-406. (in Russ.)

(C) Talitskaya A. A., Ananeva I. I., 2020

This is an open access article under the CC BY license (https://creativecommons.org/licenses/by/4.0/) 


\title{
Понятия лингвистической экспертизы в обыденном языковом сознании
}

\author{
А. А. Талицкая ${ }^{1}$, И. И. Ананьева ${ }^{1}$
}

1Ярославский государственный университет им. П.Г. Демидова, ул. Советская, 14, Ярославль, 150003, Российская Федерация

DOI: $10.18255 / 2412-6519-2020-4-396-406$

УдК 81

Научная статья

Полный текст на русском языке

В статье указывается на необходимость изучения лексики, активно используемой в спорных текстах, предоставленных на исследование лингвистам-экспертам. Объектом рассмотрения являются такие понятия лингвистической экспертизы, как брань, инвектива, клевета, имеющие словесное выражение. Выявляются особенности восприятия указанных лексем обыденным языковым сознанием. Психолингвистическое описание исследуемых понятий осуществляется на основе результатов психолингвистического эксперимента, проведенного с помощью метода свободного ассоциативного эксперимента. Авторами составлены ассоциативные поля данных лексем, выделены семантические группы, сформулированы психолингвистические значения. Проведено сопоставление лексикографического описания лексем и экспериментальных данных. Лексикографическое описание лексем осуществляется как на базе толкового словаря русского языка, так и с помощью юридических словарей, словарей литературоведческих понятий, словаря арго и т. д. Поднимаются проблемы разграничения значений юридических понятий и повышения юридической грамотности носителей языка. Показано, что исследуемые лексемы в целом хорошо усвоены языковым сознанием носителей языка (за исключением лексемы инвектива) и что их юридический аспект частично осознается испытуемыми. Делаются выводы о важности проведения психолингвистических исследований в практике лингвистической экспертизы, т. к. они позволяют уточнить значение юридических понятий и показать особенности восприятия таких понятий обыденным языковым сознанием.

Ключевые слова: языковое сознание; психолингвистический эксперимент; ассоциативное поле; семантическая группа; бранная лексика; инвективная лексика; клевета; оскорбление

\section{ИНФОРМАЦИЯ ОБ АВТОРАХ}

Талицкая, Анна Александровна

Email: cliver_08@bk.ru

Кандидат филологических наук, доцент, доцент кафедры общей и прикладной филологии

Ананьева, Ирина Ивановна Email: yairina.ananeva@yandex.ru

Магистрант факультета филологии и коммуникации

Для цитирования: Талицкая А. А., Ананьева И. И. Понятия лингвистической экспертизы в обыденном языковом сознании // Социальные и гуманитарные знания. 2020. Том 6, № 4. С. 396-406.

(C) Талицкая А. А., Ананьева И. И., 2020

Статья открытого доступа под лицензией СС BY (https://creativecommons.org/licenses/by/4.0/) 
В последние десятилетия увеличивается количество учёных, проявляющих интерес к лингвистической экспертизе текстов. Ведущий российский специалист в области лингвистической экспертизы профессор А. Н. Баранов отмечает, что в широком смысле язык области права включает термины двух типов: «получающие определение в рамках соответствующих законов» и термины, «определения которых в нормативных и законодательных документах отсутствуют» [1, с. 20]. Значения последних, таким образом, можно определить, привлекая информацию о том, какие значения слова и выражения, включённые в термин, «имеют в современном русском литературном языке или в одном из его подъязыков» [1, С. 20].

Одним из объектов лингвистической экспертизы является лексика, включённая в так называемые эмоциональные тексты. Изучение такой лексики - серьёзная, а вместе с тем актуальная проблема современной лингвокриминалистики. Эмотивный компонент семантики языка рассматривается «в составе его культурологического аспекта, так как отражение эмоций в языке национально специфично». [2, с. 40]. Эмоциональное состояние может быть репрезентировано в языке различными способами. Один из них, по мнению Шаховского, - непосредственное выражение (междометия, инвективная лексика и пр.) [2, С. 34].

Важно понимать, как термины, применяемые в лингвистической экспертизе текстов, воспринимаются обыденным языковым сознанием носителей языка, так как вопросы, выносимые на заключение эксперта-лингвиста, часто обусловлены расхождением понимания значения в юридическом и обыденном смыслах. Под языковым сознанием И.А.Стернин понимает «часть сознания, обеспечивающую механизмы языковой (речевой) деятельности: порождение речи, восприятие речи и хранение языка в сознании» [3, с. 50]. Языковое сознание является предметом изучения психолингвистики, оно исследуется экспериментально.

В статье рассматриваются некоторые понятия лингвистической экспертизы, значения которых связаны со словесным выражением и которые воспринимаются в контексте оценочного речевого акта с негативной коннотацией в обыденном языковом сознании.

Целью статьи является психолингвистическое описание лексем брань, инвектива, клевета и их сопоставление с лексикографическим толкованием и юридической практикой их употребления.

Методом исследования выступает свободный ассоциативный эксперимент, методика проведения которого изложена в [4; с. 127].

В психолингвистическом эксперименте приняли участие 136 человек (36 мужчин и 100 женщин) - жителей Вологодской, Ленинградской и Ярославской областей. Из них 61 человек - в возрасте от 15 до 30 лет, 45 человек - в возрасте от 30 до 50 лет и 30 человек - в возрасте от 50 до 86 лет.

Испытуемым был предложен список слов-стимулов и инструкция: «Просим Вас принять участие в психолингвистическом эксперименте. Пожалуйста, прочитайте предлагаемый список слов и около каждого напишите первое слово, которое придёт Вам в голову. Не раздумывайте долго. Если ни одно слово не вспоминается, ставьте прочерк». В конце анкеты респонденты указывали свой возраст, пол и социальное положение.

Результаты ассоциативного эксперимента были обработаны по частотности и представлены в виде ассоциативного поля. 


\section{БРАНЬ}

\section{Ассоциативное поле}

Брань 136 - ругань 42; мат 22; ругательство 10; ссора 7; срань 4; с*ка 3; б*я; б*ть; радость; ругательства; стол 2; бабушка; батарея; безобразное качество; больной; вздор; гаражи; грязь; дом; кактус; колье; крик; лень; любовь; магазин; мяч; невоспитанность; нос; окно; оскорбление; п*дец; плохие слова; подруга; поле брани; ппц; разговор; ругательство в сторону того, кто подвел или сделал что-то плохое, или случилось что-то не предвиденное и пошло по кривой; ругаться; скандал; снег; спор; сражение; Сызрань; ужас; унижение; хрень; Челябинск 1.

Отказы - 3 (реакции на стимул брань отсутствовали).

Всего 133 реакции. Из них различных - 47. Один респондент привёл полную словесную дефиницию.

\section{Семантическая интерпретация результатов эксперимента}

Ассоциативные реакции были распределены по семантическим группам (расположены в порядке убывания количества реакций в группе).

1. Синонимические обозначения: ругань 56 (ругань 42; ругательство 10; ругательства 2; ругательство в сторону того, кто подвел или сделал что-то плохое, или случилось что-то не предвиденное и пошло по кривой 1 ; ругаться 1); мат 22; плохие слова 1. Всего 79 реакций.

2. Конфликтная ситуация (во время которой можно услышать брань): ссора 8 (ссора 7; скандал 1); вздор; крик; спор 1. Всего 11 реакций.

3. Примеры бранных слов, по мнению респондентов: с*ка 3; б*я; б*ть 2; пдец; ппц; хрень 1. Всего 10 реакций.

4. Неодобрительная оценка: срань 4; безобразное качество; грязь; невоспитанность; ужас 1. Всего 8 реакций.

5. Конкретное место, локация, где можно услышать брань: стол 2; гаражи; дом; магазин; Сызрань; Челябинск 1. Всего 7 реакций.

6. Воздействие на собеседника: оскорбление 1; унижение 1. Всего 2 реакции.

7. Человек, являющийся источником брани: бабушка; подруга 1. Всего 2 реакции.

8. Реакции к омониму, обозначающему битву, бой: поле брани; сражение 1. Всего 2 реакции.

Не интерпретируются следующие реакции, связанные с личным опытом испытуемых: радость 2; батарея; больной; кактус; колье; лень; любовь; мяч; нос; окно; разговор; снег 1 . Всего 13 реакций.

Сформулируем психолингвистическое описание значения слова БРАНЬ (136 ии) по результатам эксперимента:

1. То же что ругань 56 , мат 22 , плохие слова 1 , звучат в конфликтных ситуациях 11 (ссора 7; скандал 1; вздор; крик; спор 1), используется за столом 2, в гаражах 1, дома 1 , в магазине 1 , в Сызрани, в Челябинске 1 бабушкой 1 , подругой 1 , например, с* ка 3 , $\sigma^{*} я$, 2 , б*т 2 , п*дец 1 , ппц 1 , хрень 1 , оценивается неодобрительно 8 , воздействует на собеседника как оскорбление 1 , унижение 1.

2. Поле брани 1 ; сражение 1. 
Не интерпретируются - 13 реакций.

Отказы - 3 реакции.

С понятием лингвистической экспертизы соотносится первое из выделенных нами психолингвистических значений лексемы брань.

Для лексикографического описания лексемы мы использовали Большой толковый словарь русского языка под редакцией С. А. Кузнецова:

Брань - оскорбительные, грубые слова; ругань [5].

Результаты психолингвистического эксперимента показывают, что большинство респондентов ассоциируют брань с синонимичными понятиями (самая объёмная семантическая группа), среди которых доминирующим является 'ругань'. Лексикографическое описание лексемы также содержит этот синоним. Брань с руганью ассоциируют респонденты всех возрастов, что говорит о том, что значение лексемы закреплено в языковом сознании испытуемых.

Ассоциация 'мат' из первой семантической группы также частотна в анкетах респондентов, причём превалирует в возрастной группе испытуемых до 35 лет. Большой толковый словарь русского языка под редакцией С. А. Кузнецова содержит следующее определение лексемы:

Мат - разг. Неприличная, оскорбительная брань; сквернословие [5].

Соответственно, в разговорном стиле бранная лексика и мат синонимичны. Это подтверждают примеры слов-ассоциаций из третьей семантической группы: $\sigma^{*} я$, $\sigma^{*}$ ть 2; пи*дец 1.

В списке основных понятий лингвокриминалистической экспертизы из справочного пособия под редакцией И.А.Стернина бранная лексика определяется как «слова и выражения, содержащие резкую обобщенную неодобрительную оценку объекта номинации - лица, явления, предмета (мерзавец, дерьмо, говно, засранец, козел, сволочь, сука, тварь, гнида и под.)» [6, с. 5]. Синонимом слова бранный в словарной статье выступает слово инвективный. В словарной статье содержится информация о функционировании бранной лексики в речи: «применительно к человеку она может употребляться с намерением оскорбить или унизить адресата, а может использоваться и без такого намерения, безадресно, для спонтанного выброса эмоций» [6, С. 5].

Семантическая группа, содержащая конкретные примеры бранных слов, которые привели респонденты, содержит слово, которое можно отнести к бранному - с*ка (причём ассоциация не единична). Неодобрительная оценка, с которой испытуемые ассоциируют брань, выражена в 4-й семантической группе. Ассоциация 'срань' зафиксирована как лексема в словаре русского арго под редакцией В. С. Елистратова («чтото плохое, дурное» [7]).

Один испытуемый ассоциировал брань с оскорблением. Таким пониманием значения брани обусловлены экспертизы, в которых лингвисту необходимо разграничить диагностические признаки оскорбления и брани. Авторы пособия отмечают, что «использование бранной лексики осуждается общественным сознанием с морально-этической точки зрения» [6, с. 5]. Вторая семантическая группа, выделенная по результатам эксперимента, содержит примеры ситуаций, в которых может быть употреблена бранная лексика, пятая - описывает локации (в том числе - общественные места), где также, по мнению испытуемых, можно столкнуться с употреблением брани. В бытовом смысле слова человек, в адрес которого употреблено бранное слово, может обидеться, поэтому с точки зрения культуры речи это считается речевым оскорблением (правовому регулированию факт такого оскорбления не подлежит). 
Единичная ассоциация 'оскорбление', выявленная в ходе обработки результатов психолингвистического эксперимента, показывает, что понимание об оскорблении человека бранными словами присутствует в обыденном языковом сознании носителей языка.

Психолингвистическое значение лексемы выявило не зафиксированные в её лексикографических описаниях семантические компоненты: респонденты приводят ассоциации, связанные с людьми, являющимися источником брани. Однако эти реакции единичны (бабушка; подруга 1) и, скорее всего, связаны со стереотипами (бабушка бранит внука) или конкретной коммуникативной ситуацией.

Реакции, обозначающие битву, также единичны - их наличие объясняется омонимичностью лексемы.

Таким образом, в обыденном сознании брань - это прежде всего ругань 56 и мат 22, которые возникают в конфликтных ситуациях 11. Это доминантные семантические компоненты лексемы брань в языковом сознании рядового носителя языка.

Лексикографическое значение - это ругань, грубые слова.

Психолингвистическое и лексикографическое значение в целом совпадают, они толкуются через синоним ругань, но в реальном языковом сознании брань дополнительно связывается с конфликтными ситуациями, в которых она возникает, а также отождествляется с матом. Брань оценивается неодобрительно 9, рассматривается как оскорбление 1 и унижение 1 собеседника. Для обыденного сознания также оказывается важным место, где можно услышать брань и лица, которые могут браниться. Психолингвистическое значение шире и глубже лексикографического.

Юридического определения слова брань нет.

\section{ИНВЕКТИВА}

\section{Ассоциативное поле}

Инвектива 136 - оскорбление; что это? 5; инъекция; обвинение; перспектива; снег 3; мысль; неизвестность; памфлет 2; бидон; боль; брань; буквы; гнев; деньги; доброта; дом; дрянь; дурачина; земля; канал а-оnе; ковёр; концерт; критика; литература; мост; наезд; небо; несправедливость; обед; обличение; осмеивание; осмеять; очки; послесловие; прочерк; размышление; ругательство; сарказм; слабак; собака; счастье; теория; укол; хорошее слово; чиновники; что такое? 1.

Отказы - 71 (реакции на стимул инвектива отсутствовали).

Всего 66 реакций. Из них различных - 48.

\section{Семантическая интерпретация результатов эксперимента}

1. Форма высказывания (в основном критического), форма литературного произведения: мысль 3 (мысль 2; размышление 1); осмеивание 3 (осмеивание 1; осмеять 1; сарказм 1); памфлет 2; критика; литература; послесловие 1 . Всего 11 реакций.

2. Воздействие на собеседника: оскорбление 5; обвинение 3 ; обличение; наезд 1. Всего 10 реакций.

3. Примеры инвективных слов, по мнению респондентов: дрянь; дурачина; слабак; собака 1. Всего 4 реакции.

4. Чувства: боль; гнев; несправедливость 1. Всего 3 реакции.

5. Синонимические обозначения: брань; ругательство 1. Всего 2 реакции. 
Не интерпретируются следующие реакции, связанные с личным опытом испытуемых, а также реакции, содержащие вопрос типа «что это?»: что это? 5; инъекция; перспектива; снег 3; неизвестность 2; бидон; буквы; деньги; доброта; дом; земля; канал а-оnе; ковёр; концерт; мост; небо; обед; очки; прочерк; счастье; теория; укол; хорошее слово; чиновники; что такое? 1. Всего 36 реакций.

Сформулируем психолингвистическое описание значения слова ИНВЕКТИВА (136 ии) по результатам эксперимента:

1. То же, что брань 1, ругательство 1, воздействующие на собеседника посредством оскорбления 5 , обвинения 3 , обличения 1 , наезда 1 , например, дрянь 1 , дурачина 1 , слабак 1 , собака 1 , связано с чувством боли 1 , гнева 1 , несправедливости 1.

2. Форма критического 1 высказывания в виде мысли 3 (мысль 2; размышление 1), осмеивания 3 (осмеивание 1 ; осмеять 1; сарказм 1), форма литературного произведения в виде памфлета 2, послесловия 1.

Не интерпретируются - 36 реакций.

Отказы - 71 реакция.

С понятием лингвистической экспертизы связано первое из выделенных нами психолингвистических значений лексемы инвектива.

Большой толковый словарь русского языка под редакцией С. А. Кузнецова предлагает следующее значение лексемы: речь [5].

Инвектива - резкое выступление против кого-, чего-л.; оскорбительная

Вторая по объёму семантическая группа, выявленная в ходе обработки анкет, содержит сему 'оскорбление', которая также присутствует в лексикографическом описании.

Обратимся к списку понятий лингвокриминалистической экспертизы:

Инвектива - речевое высказывание, содержащее бранную (сволочь, мерзавец, подлец, дерьмо, говно, засранец, козел, сука, урод, тварь, гнида и под.) или нецензурную лексику, используемое для резкой обобщенной неодобрительной оценки объекта номинации - лица, явления, предмета, для понижения его общественного статуса $[6$, с. 14].

Данное значение лексемы находит отражение в пятой (респонденты ассоциируют инвективную лексику с бранной), а также в третьей (содержит слова, которые, по мнению испытуемых, можно считать инвективными) семантических группах.

Применительно к человеку инвектива «может употребляться с намерением оскорбить, унизить адресата, а может использоваться и без такого намерения, безадресно» [Там же. С. 14]. Этот аспект значения лексемы выявлен во второй семантической группе.

В целом можно говорить о слабой степени закреплённости значения лексемы инвектива в языковом сознании респондентов: менее половины испытуемых дали реакции на слово-стимул, при этом 36 были отнесены к неинтерпретируемым. В основном реакции на исследуемый стимул привели респонденты с возрастным показателем $30+$.

Самая объёмная семантическая группа содержит ассоциации, связанные с формой литературного произведения. Литературный энциклопедический словарь под редакцией В. М. Кожевникова, П. А. Николаева содержит значение, не актуальное для Большого толкового словаря русского языка под редакцией С. А. Кузнецова, - 
«бранная речь, резкое обличение (в частности, сатирическое осмеяние) реального лица или группы лиц; противостоит панегирику (в широком значении)» [8]. Такое значение содержится и в словаре литературоведческих терминов под редакцией И. А. Книгина [9].

Толковый словарь под редакцией Т.Ф.Ефремовой определяет инвективу как многозначное слово:

1. Гневное, резкое - устное или письменное - выступление против кого-либо или чего-либо; обвинение, обличение, оскорбление, брань.

2. Разновидность сатиры; памфлет [10].

Лексикографические описания показывают, что второе значение лексемы связано с формой литературного произведения. На связь с литературой указали испытуемые в возрастном диапазоне в основном от 20 до 30 лет, преимущественно - студенты (причём как гуманитарных (юриспруденция, история), так и технических (механизация, инженерия) специальностей).

В ходе психолингвистического эксперимента также выделена группа слов, обозначающих чувства, не зафиксированная в лексикографических описаниях лексемы.

Таким образом, в языковом сознании испытуемых лексема инвектива оказывается многозначной. То же зафиксировано и в лексикографическом описании слова. В основном испытуемые связывают инвективу с формой высказывания и литературного произведения 11, однако ими также признаётся факт воздействия на собеседника 10.

Юридического толкования лексемы инвектива нет.

\section{КЛЕВЕТА}

\section{Ассоциативное поле}

Клевета 136 - ложь 49; враньё 16; обман 10; наговор; поклёп 5; суд 3; дверь; неправда; оговор; оскорбление 2; балабол; благополучие; блеф; брехня; бывает; вокзал; глаз; добро; дом; донос; заговор; квартира; креветка; лгун; лебеда; ложные обвинения в сторону невиновного; люди; маета; метель; мухомор; непорядочность; низость; обзывательство; оболгать; окно; осквернение; п*дёж; плохой; предательство; привет; радость; ругань; сестра; снег; сплетни; уважение; с*ка; часы 1.

Отказы - 2 (реакции на стимул клевета отсутствовали).

Всего 134 реакции. Из них различных - 48. Один испытуемый дал полную словесную дефиницию на слово-стимул.

\section{Семантическая интерпретация результатов эксперимента}

1. Намеренное искажение правды, истины: ложь 72 (ложь 49; враньё 16; неправда 2; брехня; донос; оболгать; п*дёж; сплетни 1); обман 23 (обман 10; наговор; поклёп 5; оговор 2; блеф 1). Всего 95 реакций.

2. Неодобрительная оценка: балабол; непорядочность; лгун; низость; обзывательство; плохой; ругань; с* ка 1 . Всего 8 реакций.

3. Неучтивый поступок: оскорбление 2; осквернение; предательство 1 . Всего 4 реакции.

4. Связь с судебным процессом: суд 3 ; ложные обвинения в сторону невиновного 1. Всего 4 реакции. 
5. Ситуация: маета; заговор 1 . Всего 2 реакции.

Не интерпретируются следующие реакции, связанные с личным опытом испытуемых: дверь 2; благополучие; бывает; вокзал; глаз; добро; дом; квартира; креветка; лебеда; люди; метель; мухомор; окно; привет; радость; сестра; снег; уважение; часы 1. Всего 21 реакция.

\section{Сформулируем психолингвистическое описание значения слова КЛЕВЕТА} (136 ии) по результатам эксперимента:

Намеренное искажение правды 95 (ложь 72; обман 23), неучтивый поступок в виде оскорбления 2, осквернения 1, предательства 1 в ситуации маеты 1, заговора 1 , оценивается неодобрительно 8, рассматривается судом как ложное обвинение в сторону невиновного 1.

Не интерпретируются - 21 реакция.

Отказы - 2 реакции.

В Большом толковом словаре русского языка под редакцией С. А. Кузнецова зафиксировано следующее значение лексемы:

Клевета - ложное обвинение; заведомо ложный слух, позорящий кого-л.; распространение таких слухов [5].

Самая объёмная по результатам эксперимента семантическая группа содержит доминирующую сему 'ложь', которая актуальная и для словарного значения словастимула.

Также для лексикографического описания был использован Большой юридический словарь, поскольку понятие клеветы активно применяется в юриспруденции, в частности - в теории и практике лингвистической экспертизы:

Клевета - по уголовному праву РФ распространение заведомо ложных сведений, порочащих честь и достоинство другого лица или подрывающих его репутацию (ст. 129 УК РФ) [11].

Некоторые респонденты указали на связь с судебным процессом (четвертая семантическая группа), что говорит о понимании испытуемыми юридического контекста, в рамках которого может быть рассмотрено понятие клеветы.

Авторы пособия «Основные понятия лингвокриминалистической экспертизы» приводят такое же определение лексемы, ссылаясь на 129 статью УК РФ, однако добавляя диагностические признаки клеветы: «Тот, кто сообщает не соответствующие действительности порочащие сведения, знает, что они ложны и намеренно их распространяет. Если лицо, которое распространяло не соответствующие действительности сведения, было уверено в их истинности, то действия этого лица не образуют состав преступления клеветы» [6, с. 15].

Две ассоциативные реакции 'оскорбление', которые дали испытуемые, наводят на мысль о том, что не всеми гражданами усваивается различие в толковании юридических терминов оскорбления и клеветы. Оскорбление не обязательно содержит диагностический признак заведомо ложного характера распространяемых сведений, что для диагностирования клеветы в тексте обязательно, а клевета, к примеру, не обязательно может быть выражена в неприличной языковой форме (оклеветать можно и нормативной лексикой), чего нельзя сказать об оскорблении, для которого диагностический признак сообщения негативной информации, выраженной в неприличной языковой форме, обязателен. 
Психолингвистическое значение выявило семы, связанные с ситуацией и неодобрительной оценкой, которые не нашли отражения в лексикографических описаниях лексемы.

Таким образом, в языковом сознании испытуемых клевета - это в первую очередь намеренное искажение правды 95, которое оценивается неодобрительно 8. Лексикографическое описание слова дополняется обозначением процесса распространения заведомо ложных сведений, а юридическое толкование указывает на то, что такие сведения будут считаться клеветой, если порочат честь и достоинство человека или подрывают его репутацию.

Проанализировав три лексемы, связанные со словесным выражением в контексте речевого акта с (как правило) негативной коннотацией, можно сделать вывод о значимости использования результатов психолингвистических исследований в области лингвокриминалистической экспертизы. Не все аспекты юридических компонентов значений лексем находят отражение в языковом сознании граждан: так, некоторые пары понятий (к примеру, клевета и оскорбление, брань и оскорбление) воспринимаются как синонимы или воспринимаются в значении «то же», что является ошибочным. А, к примеру, на реальную синонимическую связь брани и инвективы указал лишь один респондент, дав реакцию на стимул инвектива. В психолингвистическом значении лексемы брань указание на синонимичные отношения с понятием инвективы отсутствует.

В целом можно сказать о том, что значения лексем брань и клевета закреплены в языковом сознании респондентов всех возрастов. На это указывает количество отказов (три и два соответственно), количество различных реакций (47 и 48), а также ядерные семы, входящие в самые объёмные семантические группы, выделенные при интерпретации результатов эксперимента. Причём ядерные реакции, представленные через множество синонимичных понятий, не единичны. Эти показатели позволяют сделать вывод о наличии юридической грамотности у представителей всех возрастных групп.

Значение лексемы инвектива слабо освоено носителями языка: в числе неинтерпретируемых реакций большое число составляют реакции типа «что это?».

Также стоит отметить, что семантическая интерпретация результатов эксперимента включает семантические группы, связанные с чувствами, оценками, качествами личности при описании всех исследуемых лексем, что говорит о связи с конкретным коммуникативным актом. Закон такие субъективные понятия и связи не рассматривает.

Сопоставление значений, выявленных в ходе психолингвистического эксперимента, с лексикографическим и юридическим толкованием этих лексем показывает, что психолингвистические и лексикографические значения ближе друг к другу, но психолингвистическое значение объемней лексикографического и содержит больше дифференциальных сем, оно ближе к обыденному сознанию.

Юридическое толкование, если оно есть (например, у слова клевета), содержит меньше компонентов и более точно. При оценке наличия в тексте клеветы важно, чтобы эксперт опирался на юридическое понимание термина. Если слова не определены в юриспруденции, опираться следует на научные определения лингвистов (инвектива). Если научного определения нет, следует опираться на обыденное значение в языковом сознании.

Исследование лексем с бытовым и юридическим значением важно для теории и практики лингвокриминалистической экспертизы, так как позволяет экспертам- 
лингвистам не только рассмотреть смысл того или иного слова или выражения в понимании закона, но и наметить пути повышения юридической грамотности носителей языка и сформулировать более точные, конкретные диагностирующие признаки, на предмет наличия/отсутствия которых текст может быть проанализирован не только профессиональным языковым сознанием.

\section{Ссылки / References}

1. Баранов А. Н. Лингвистическая экспертиза текста: теория и практика: учеб. пособие. М.: Флинта: Наука, 2007. 592 с.

2. Шаховский В. И. Эмоции как объект исследования в лингвистике // Вопросы психолингвистики / Глав. ред. Е. Ф. Тарасов. М.: Ин-т языкознания РАН, 2009. С. 29-43.

3. Стернин И. А. Коммуникативное и когнитивное сознание // С любовью к языку / Отв. ред. В. А. Виноградов. М.: Ин-т языкознания РАН, 2002. С. 44-51.

4. Стернин И. А., Рудакова А. В. Психолингвистическое значение слова и его описание. Воронеж: Ламберт, 2011. 192 с.

5. Большой толковый словарь русского языка / Сост. и гл. ред. С. А. Кузнецов. СПб.: Норинт, 2000. 1536 c.

6. Выявление признаков унижения чести, достоинства, умаления деловой репутации и оскорбления в лингвистической экспертизе текста / И. А. Стернин, Л. Г. Антонова, Д. Л. Карпов, М. В. Шаманова; под науч. ред. проф. И. А. Стернина. Ярославль, 2013. 35 с.

7. Елистратов В. С. Словарь русского арго. URL: http://endic.ru/russian_argo/Sran-1645.html (дата обращения: 28.08.2020).

8. Литературный энциклопедический словарь / [подгот. Е. И. Бонч-Бруевич и др.]; под общ. ред. В. М. Кожевникова, П. А. Николаева. М.: Сов. энцикл., 1987. 75 с. URL: http://niv.ru/doc/encyclopedia/literature/index.htm (дата обращения: 28.08.2020).

9. Словарь литературоведческих терминов / Сост. И. А. Книгин. Саратов: Лицей, 2006. $270 \mathrm{c}$.

10. Ефремова Т. Ф. Современный толковый словарь русского языка: в 3 т.: около 160000 слов. М.: Астрель: АСТ, 2006. 636 с.

URL: https://gufo.me/dict/efremova/\%D0\%B8\%D0\%BD\%D0\%B2\%D0\%B5\%D0\%BA\%D1\% 82\%D0\%B8\%D0\%B2\%D0\%B0 (дата обращения: 28.08.2020).

11. Большой юридический словарь / Под ред. А. Я. Сухарева, В. Е. Крутских. 2-е изд., перераб. и доп. М.: ИНФРА-М, 2003. 703 c. URL: http://law.niv.ru/doc/dictionary/big-legal/fc/slovar202-2.htm\#zag-2778 (дата обращения: 28.08.2020). 